\title{
Evaluasi Kapabilitas Sistem Informasi Manajemen Akuntansi Barang Milik Negara di Satuan Kerja TNI Angkatan Laut
}

\author{
Suhardi $^{* 1)}$, Zulfa Fitri Ikatrinasari ${ }^{2)}$ \\ 1) ${ }^{2)}$ Program Studi Magister Teknik Industri, Universitas Mercu Buana \\ Jakarta 11650, Indonesia
}

\begin{abstract}
Information Technology (IT) on Government good Accounting management of Information System (SIMAK BMN) is a computer system built by economic ministry. SIMAK BMN in government is a needed information system as a tool to responsible of using APBN, and it's a function to serve a result of economic report transparently and accountable. A military SIMAK BMN reported by work unit of Navy as unit of accounting unit which using good responsibility. It's determine the opine adjustment of BPK RI such as proper without exception (WTP), Proper with Exception (WDP), It does not proper, and disclaimer. Using SIMAK BMN in UAKPB has an important position. But it has never been determined so it has never known it's efficiently and capability of managing the information technology. Knowing the problem is needs a research and finding to know how far the determined result of capability process SIMAN BMN information technology. The research is repairing management and the system is used optimally. The research method is using framework COBIT5. The method is the way how it determines the respondent answer from questioners which is built using Monitor Domain, Evaluate and Assess (MEA). It is focusing on a watch, adjust, and regularly of all information technology system used. According to the answer from responder, it will be got the level capability MEAO1 is 3,71, MEAO2 is 2,38, and MEAO3 is 3,67. The average score is 3,26. It is in level 3 (Established process) form 0-5. Getting the hoping capability, it is advised by developing performance of SIMAK BMN information technology in the future.
\end{abstract}

Keywords: SIMAK BMN, COBIT5, level capability, domain MEA

\section{Pendahuluan}

Perkembangan Teknologi Informasi (TI) saat ini sangat cepat, khususnya pada suatu instansi atau organisasi yang sangat membutuhkan suatu informasi untuk pengambilan keputusan. Teknologi Informasi (TI) dapat diibaratkan sebagai darah yang mengalir di dalam tubuh manusia, yang sangat penting untuk mendukung kelangsungan perkembangannya sehingga informasi sangat dibutuhkan dalam mengolah data. Pengolahan data memerlukan suatu sistem agar informasi yang diperoleh berkualitas dan bernilai bagi instansi yang bersangkutan. Di era globalisasi yang sudah berlangsung pada saat ini peran TI merupakan kenyataan yang tidak dapat dihindari termasuk kelebihan dan kekurangannya. Menurut O'Brien (2006) Sistem informasi dan teknologi telah menjadi komponen yang sangat penting bagi keberhasilan bisnis dan organisasi. Hal ini menyebabkan perubahan sistem pada instansi atau perusahaan, yang berdampak juga pada perubahan cara kerja mereka. Teknologi informasi banyak diterapkan untuk pengelolaan pekerjaan karena daya efektivitas dan efisiensinya yang sudah terbukti mampu mempercepat kinerja. Teknologi informasi saat ini telah menyebar hampir di

*Correspondance : 
semua aspek kehidupan dan profesi, tidak terkecual di dalam pengelolaan barang milik negara $(\mathrm{BMN})$ di lingkungan Pemerintah.

Dalam Undang-undang Nomor 1 tahun 2004 tentang Perbendaharaan Negara, Sistem Akuntansi Instansi (SAI) memiliki dua subsistem dalam pelaksanaannya, yaitu Sistem Akuntansi Keuangan (SAK) dan Sistem Informasi Manajemen dan Akuntansi Barang Milik Negara (SIMAK-BMN). SAK dan SIMAK-BMN beserta beberapa aplikasi keuangan lainnya diintegrasikan menjadi satu aplikasi yaitu aplikasi Sistem Aplikasi Keuangan Tingkat Instansi (SAKTI) sebagai salah satu implementasi Sistem Perbendaharaan dan Anggaran Negara (SPAN). Sistem informasi manajemen akuntansi keuangan, yang selanjutnya disingkat SIMAK adalah aplikasi keuangan berdasarkan sistem akuntansi keuangan (SAK). Sedangkan aplikasi SIMAK barang milik Negara (BMN) berdasarkan pada sistem akuntansi barang milik Negara (SABMN) yang diselenggarakan dengan tujuan untuk menghasilkan informasi yang diperlukan sebagai alat pertanggung jawaban atas pelaksanaan APBN serta pengelola/pengendalian BMN yang dikuasai oleh suatu unit akuntansi pengguna barang. Pertanggung jawaban kementrian/lembaga pemerintahan pelaksanaannya dimulai pada intansi terkecil yaitu tingkat satuan kerja Unit Akuntansi Kuasa Pengguna Barang (UAKPB) sampai pada tingkat kementrian. Mengingat pentingnnya SAI dalam pelaporan keuangan pemerintah yang merupakan bagian dari pertangung jawaban yang tidak terpisahakan dalam penyelenggaraan pemerintahan dalam pembangunan, maka SAK dan SABMN dilakukan menggunakan sistem komputerisasi dengan menggunakan aplikasi tersendiri rancangan departemen keuangan RI. Agar mempermudah setiap jenjang unit akuntansi menyampaikan laporan keuangan kepada jenjang di atasnya, sehingga terjadi transparasi dan akuntabilitas kepada publik.

Sejak adanya regulasi tentang pengeloaan barang milik negara, maka dalam pertanggung jawaban pengelolaan barang milik negara harus diakukan dengan tertib dan benar. Upaya untuk membenahi laporan barang milik negara selalu ditingkatkan dari tahun ketahun. Salah satu upaua peningkatan pengelolaam barang milik negara adalah menerbitkan opini terhadap laporan keuangan instansi pemerintah oleh auditor BPK RI.

Laporan keuangan Kementrian Pertahanan (Kemhan) pada tahun 2013 menghasilkan opini audit Wajar Tanpa Pengecualian (WTP), yang pada tahun sebelumnnya menghasilkan opini Wajar Dengan Pengecualian (WDP). Opini WTP ini menunjukan bahwa laporan keuangan pada Kementerian Pertahanan dianggap memberikan informasi yang bebas dari salah saji material. Laporan keuangan menjadi WTP, artinya auditor meyakini berdasarkan bukti-bukti audit yang dikumpulkan, pemerintah dianggap telah menyelenggarakan prinsip akuntansi yang berlaku umum dengan baik, dan kalaupun ada kesalahan, kesalahannya dianggap tidak berpengaruh signifikan terhadap pengambilan keputusan. Meskipun terlihat pada pemeriksaan BPK RI atas laporan keuangan Kementrian Pertahanan (Kemhan) tahun 2013 menyatakan mekanisme penyusunan laporan barang milik Negara belum optimal dalam mendukung penyajian neraca Kemhan. Badan Pemeriksa Keuangan Republik Indonesia (BPK RI) mengeluarkan rekomendassi agar melaksanakan sosialisasi dan pelatihan yang berkesinambungan termasuk prosedur rekonsiliasi internal antara unit Akuntasi Kuasa Pengguna Anggaran (UAKPA) dan unit Akuntasi Kuasa Pengguna Barang (UAKPB).

Satuan Kerja (Satker) TNI Angkatan Laut sebagai Unit Akuntansi Kuasa Pengguna Barang (UAKPB) satpor terkecil adalah satuan kerja/kuasa pengguna barang yang memiliki wewenang untuk mengurus dan menggunakan Barang Milik Negara (BMN). Penyelenggaraan Sistem Informasi Manajemen Barang Milik Negara (SIMAK BMN) di 
Satker TNI Angkatan Laut masih ditemukan beberapa temuan. Dari temuan tim wasrik Itjen TNI dan Itjen TNI Angkatan Laut di atas, maka diobservasi terhadap permasalahan awal adalah sebagai berikut: (1) Proses pelaksanaan prosedur aplikasi SIMAK BMN di Satker Angkatan Laut, yang dijalankan belum optimal dan belum dapat membantu percepatan transparasi dan akuntansi pengelolaan asset tetap pemerintah. Tuntutan ini untuk menciptakan transparasi dan akuntansi, sebagaimana diamanatkan dalam tata kelola yang baik (good governance). (2) Adanya perubahan penggunaan Aplikasi SIMAK BMN versi Kemhan ke penggunakan SIMAK BMN versi Kemenku, yang mana berakibat pencatatan nilai asset tetap berubah sehingga data belum valid pada data awal dengan data perolehan riil aset yang ada. (3) Belum adanya penelitian yang secara khusus melakukan pengukuran penggunaan SIMAK BMN di Satker TNI Angkatan Laut, sehingga belum bisa melihat secara utuh permasalahan yang terjadi pada pengelolahan SIMAK BMN tersebut.

Berdasarkan uraian di atas, maka sangatlah penting untuk mengukur tingkat kapabilitas pada tata kelola TI SIMAK BMN di Satker TNI Angkatan Laut. Beberapa pendekatan dan kerangka kerja dapat digunakan untuk menilai tingkat kapabilitas sistem informasi, salah satunya adalah dengan kerangka kerja COBIT 5 (Control Objectives For Information And Related Technology versi 5). COBIT merupakan standar yang diakui dan diterima secara internasional, direkomendasikan untuk penerapan tatakelola TI yang baik. COBIT 5 adalah edisi terbaru dari Framework COBIT Information System Audit and Control Association (ISACA) yang menyediakan penjabaran bisnis secara end-to-end dari tatakelola TI pada organisasi akan tergambarkan peran utama dari informasi dan teknologi dalam menciptakan nilai organisasi (ISACA, 2012).

Beberapa penelitian tentang penilaian sistem informasi dengan COBIT telah banyak dilakukan. Nugraha (2012), Memperoleh kematangan pengembangan TI di PT XYZ melalui pengukuran dengan menggunakan kerangka Cobit 4.1 sehingga dapat dilakukan analisis perbaikan untuk meningkatkan tingkat kematangan. Suranto et al. (2014), Menggunakan COBIT 5 untuk mengetahui kepuasan pasien dan juga menilai kesesuaian sistem dengan kebutuhan yang ada di RSUD Sleman. Laksito (2012), menemukan level kapabilitas dalam area MEA di STMIK AMIKO berada pada level 1 (Perormend) dengan level target yang ingin dicapai adalah level 2 (Managed Proses). Selain itu, Jamroni (2006), Budiono (2010), Sheikhpour and Modiri (2012), Mataracioglu \& Ozkan (2012) dan Khanyile \& Abdullah (2013), juga melakukan penilaian Sistem Informasi dengan kerangka kerja COBIT dan menunjukkan manfaat bagi perbaikan proses di objek penelitiannya. Sari et al. (2014) menerapkan COBIT 5 untuk mengaudit tata kelola teknologi informasi di Kabupaten Oku. Svata (2011), meningkatkan adopsi TI dan adaptasi praktek terhadap standar perusahaan milik pemerintah pemerintah. Berdasarkan kelebihan dari COBIT 5 dan kebutuhan penilaian SIMAK BMN di Satker TNI AL, maka dilakukan penelitian yang bertujuan untuk melakukan pengukuran tingkat kapabilitas (capability level) pada Sistem Informasi Manajemen Akuntansi Barang Milik Negara (SIMAK BMN) di Satuan Kerja Angkatan Laut dengan kerangka kerja COBIT 5.

\section{Cobit (Control Objectives For Information and Related Technologi)}

COBIT dikembangkan oleh IT Governance Institute (ITGI), yang merupakan bagian dari Information Sistem Audit and Control Association (ISACA). COBIT adalah sekumpulan dokumentasi best practice untuk tata kelola TI yang dapat membantu auditor, manajemen dan pengguna untuk menjembatani gap antara resiko bisnis, kebutuhan kontrol dan permasalahan teknis. COBIT merupakan suatu cara untuk 
menerapkan Information Technology (IT) Governance. COBIT berupa kerangka kerja yang harus digunakan oleh suatu organisasi bersamaan dengan sumber daya lainnya untuk membentuk suatu standar yang umum berupa panduan pada lingkungan yang lebih spesifik. Secara terstruktur, COBIT terdiri dari seperangkat control objectives untuk bidang teknologi informasi, dirancang untuk memungkinkan tahapan bagi audit (Campbell, 2005). COBIT merupakan sekumpulan dokumentasi dan panduan yang mengarahkan pada IT governance yang membantu auditor, manajemen, dan pengguna (user) untuk menjembatani pemisah (gap) antara resiko bisnis, kebutuhan kontrol, dan permasalahan-permasalahan teknis. COBIT dikembangkan oleh IT Governance Institute (ITGI) yang merupakan bagian dari Information Systems Audit and Control Association.

Tata Kelola dan Manajemen TI COBIT 5 (ISACA, 2012)

COBIT 5 merupakan sebuah kerangka menyeluruh yang dapat membantu perusahaan dalam mencapai tejuannya untuk tata dan manajemen TI perusahaan. Secara sederhana COBIT 5 membantu perusahaan menciptakan nilai optimal dari TI dengan cara menjaga keseimbangan antara mendapatkan keuntungan dan mengoptimalkan tingkat resiko dan penggunaan sumbar daya. Hal ini tertuang dalam 5 prinsip COBIT 5 seperti pada Gambar 1 di bawah ini.

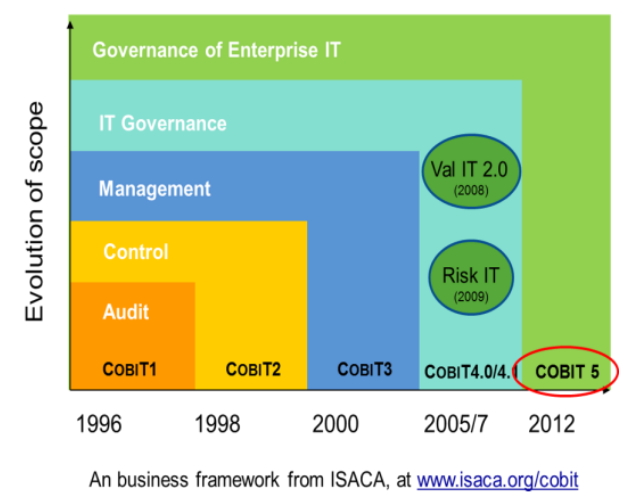

Gambar 1. Prinsip COBIT 5 (ISACA, 2012)

\section{Prinsip 1: Memenuhi Kebutuhan Stakeholder}

Perusahaan menciptakan nilai bagi para stakeholdernya dengan menjaga keseimbangan antara realisasi keuntungan dan optimasi risiko dan penggunaan sumber daya. COBIT 5 menyediakan semua proses yang dibutuhkan dan pemicupemicu lainnya untuk mendukung penciptaan nilai bisnis melalui penggunaan TI. Oleh karena itu setiap perusahaan memiliki tujuan yang berbeda, sebuah perusahaan dapat mengkustomisasi COBIT 5 agar sesuai dengan konteks perusahaan itu sendiri melalui pengaliran tujuan (goal cascade), menerjemahkan tujuan utama perusahaan menjadi tujuan yang dapat diatur, spesifik dan berhubungan dengan TI, serta memetakan tujuan-tujuan tersebut menjadi prosesproses dan praktik-praktik yang spesifik.

\section{Prinsip 2: Melingkupi Seluruh Perusahaan}

COBIT 5 mencakup semua fungsi dan proses dalam perusahaan. COBIT 5 tidak hanya fokus pada 'fungsi TI', namun memperlakukan informasi dan teknologi yang berhubungan dengannya sebagai suatu aset yang perlu ditangani oleh semua orang dalam perusahaan seperti juga aset-aset perusahaan yang lain.COBIT 5 mempertimbangkan semua pemicu untuk tata kelola dan manajemen yang berhubungan dengan TI agar dapat 
digunakan secara menyeluruh dalam perusahaan, termasuk semua orang dan semua hal internal dan eksternal yang berhubungan dengan tata kelola dan manajemen informasi dan TI perusahaan. COBIT 5 mengintegrasikan tata kelola TI perusahaan ke dalam tata kelola perusahaan.

\section{Prinsip 3: Menerapkan Suatu Kerangka Tunggal yang Terintegrasi}

Ada beberapa standar dan best practices yang berhubungan dengan TI, masing-masing menyediakan panduan dalam sebuah bagian dari aktivitas TI.

\section{Prinsip 4: Menggunakan sebuah pendekatan yang menyeluruh}

Tata kelola dan manajemen TI perusahaan yang efektif dan efisien memerlukan suatu pendekatan yang menyeluruh, dan melibatkan beberapa komponen yang saling berinteraksi. COBIT 5 mendefinisikan serangkaian pemicu untuk mendukung implementasi sistem yang komprehensif tentang tata kelola dan manajemen TI perusahaan.

\section{Prinsip 5: Pemisahan Tata kelola dari Manajemen}

Kerangka COBIT 5 memuat suatu perbedaan yang jelas antara tata kelola dan manajemen. Dua disiplin yang berbeda ini juga meliputi aktivitas yang berbeda, memerlukan struktur organisasi yang berbeda dan melayani tujuan yang berbeda pula.

\section{Model Kapabilitas Proses dalam COBIT 5}

Model kapabilitas proses dalam COBIT 5 berdasarkan pada ISO/IEC 15504, yaitu standar mengenai Software Engineering dan Process Assessment. Model ini mengukur performansi tiap-tiap proses tata kelola (EDM-based) atau proses manajemen (PBRM based), dan dapat mengidentifikasi area-area yang perlu untuk ditingkatkan performansinya.

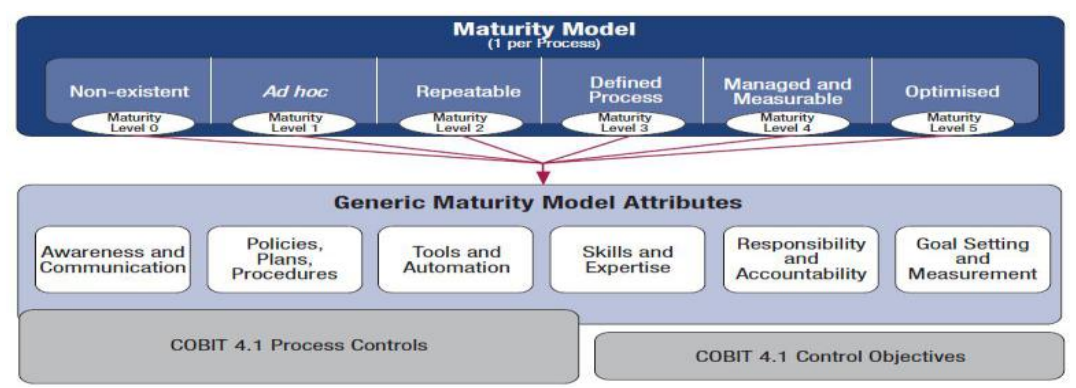

Gambar. 2. Model Kapabilitas Proses dalam COBIT 5 (ISACA, 2012)

\section{Metode Penelitian}

Tingkat kapabilitas masing-masing proses TI pada SIMAK BMN dinilai dengan menggunakan kuesioner yang berisi pertanyaan terkait pengeloaan SIMAK BMN yang dikelompokkan sesuai dengan kapabilitas pada masing-masing domain MEA. Selanjutnya dilakukan konfirmasi atas hasil kuesioner tersebut untuk memastikan keadaan saat ini pada SIMAK BMN. Responden dalam pengisian ini diberikan pilihan: Tidak benar sekali bobot nilai 0 , Ada benarnya bobot nilai 1,65, Sebagian benar 3,30 dan sepenuhnya benar 5. Responden yang mengisi kuesioner adalah Kepala Satker, Kabagum, Penanggung jawab UAKPB, Kaur SIMAK BMN, Ur Barang Bergerak dan Ur Barang Tidak Bergerak. Kuesioner berisi tentang pertanyaan-pertanyaan yang terdiri dari: (1) Monitor, Evaluate, and Access 01 (MEA01), yaitu Pengawasan, evaluasi penilaian 
kinerja proses teknologi informasi pada SIMAK BMN di Satker TNI AL terhadap kebijakan yang telah ditetapkan dan memberikan laporan yang sistematis dan tepat waktu kepada DJKN. Pada proses ini terdiri dari 5 pertanyaan. Pertanyaan dapat dilihat pada Lampiran. (2)Monitor, Evaluate, and Access 02 (MEA02), yaitu pengawasan, evaluasi dan penilaian sistem pengendalian internal, termasuk dalam merencanakan, mengatur dan menjaga standarisasi untuk penilaian pengendalian internal dan jaminan proses kegiatan, dalam dalam hal ini menyediakan program pelatihan mengenai pemanfaatan teknologi informasi dan komunikasi kepada pengguna sistem. Pada proses ini terdiri dari 8 pertanyaan. (3) Monitor, Evaluate, and Access 03 (MEA03), yaitu pengawasan, evaluasi dan penilaian sistem pengendalian ekternal yaitu mengidentifikasi dan memonitor perubahan dalam kebijakan, peraturan dan ketetapan lainnya yang harus dipenuhi dari teknologi informasi secara terus menerus. SIMAK BMN Satker TNI AL, evaluasi dan revisi mengenai kebijakan-kebijakan ini dilakukan secara rutin setiap setahun sekali, pada proses ini terdiri dari 4 pertanyaan.

Hasil penilaian, kemudian dinterpretasikan tingkat kapabilitasnya menggunakan aturan skala penilaian seperti pada Tabel 2 di bawah ini. Kemudian setelah diketahui tingkat keberhasilan penerapan IT (kapabalitas COBIT 5), maka dianalisis Kesejangan (Gap) untuk kemudian dilakukan rekomendasi.

Tabel 1. Skala Penilaian Capability COBIT 5

\begin{tabular}{ccc}
\hline Level & Range & Tingkat Model Capability \\
\hline 5 & $4,51-5$ & Optimisting Process \\
4 & $3,51-4,5$ & Predictable Process \\
3 & $2,51-3,5$ & Established Proces \\
2 & $1,51-2,5$ & Managed Process \\
1 & $0,51-1,5$ & Perfirmed Process \\
0 & $0-0,5$ & Incomplete Process \\
\hline
\end{tabular}

Sumber: Suranto et al., 2014

\section{Hasil Dan Pembahasan}

Tujuan penelitian ini mengukur tingkat kapabilitas proses TI pada SIMAK BMN di Satker TNI AL menurut framework COBIT 5 pada domain Hasil pengukuran tingkat capability pada framework COBIT 5 pada masing-masing domain berada pada tingkat 2 s/d tingkat 4. MEA01 berada pada tingkat 2, MEA02 berada pada tingkat 4, MEA03 berada pada tingkat 4, dan total MEA berada pada Capability tingkat 4 (empat). Hasil pengukuran dapat dilihat pada Tabel 3 di bawah ini.

Tabel 2. Hasil penilaian tingkat kapabilitas SIMAK BMN di Satker TNI AL

\begin{tabular}{|c|c|c|c|c|c|c|c|c|c|c|c|}
\hline \multirow[t]{2}{*}{ No } & \multirow[t]{2}{*}{ Domain } & \multirow[t]{2}{*}{ Proses } & \multicolumn{6}{|c|}{ Nilai dari Responden } & \multirow[t]{2}{*}{$\begin{array}{l}\text { Rata- } \\
\text { rata }\end{array}$} & \multirow{2}{*}{$\begin{array}{c}\text { Jml Rata- } \\
\text { rata Sub } \\
\text { proses }\end{array}$} & \multirow{2}{*}{$\begin{array}{c}\text { Rata- } \\
\text { rata } \\
\text { Proses }\end{array}$} \\
\hline & & & 1 & 2 & 3 & 4 & 5 & 6 & & & \\
\hline \multirow{4}{*}{1} & \multirow{4}{*}{ MEA01 } & $\begin{array}{l}\text { MEA01.0 } \\
1\end{array}$ & 1,65 & 5 & 0 & 3,3 & 3,3 & 0 & 2,21 & \multirow{4}{*}{18,56} & \multirow{4}{*}{3,71} \\
\hline & & $\begin{array}{l}\text { MEA01.0 } \\
2\end{array}$ & 3,3 & 5 & 0 & 5 & 5 & 3,3 & 3,60 & & \\
\hline & & $\begin{array}{l}\text { MEA01.0 } \\
3\end{array}$ & 5 & 5 & 3,3 & 5 & 5 & 5 & 4,72 & & \\
\hline & & $\begin{array}{l}\text { MEA01.0 } \\
4\end{array}$ & 3,3 & 5 & 1,65 & 5 & 5 & 5 & 4,16 & & \\
\hline
\end{tabular}




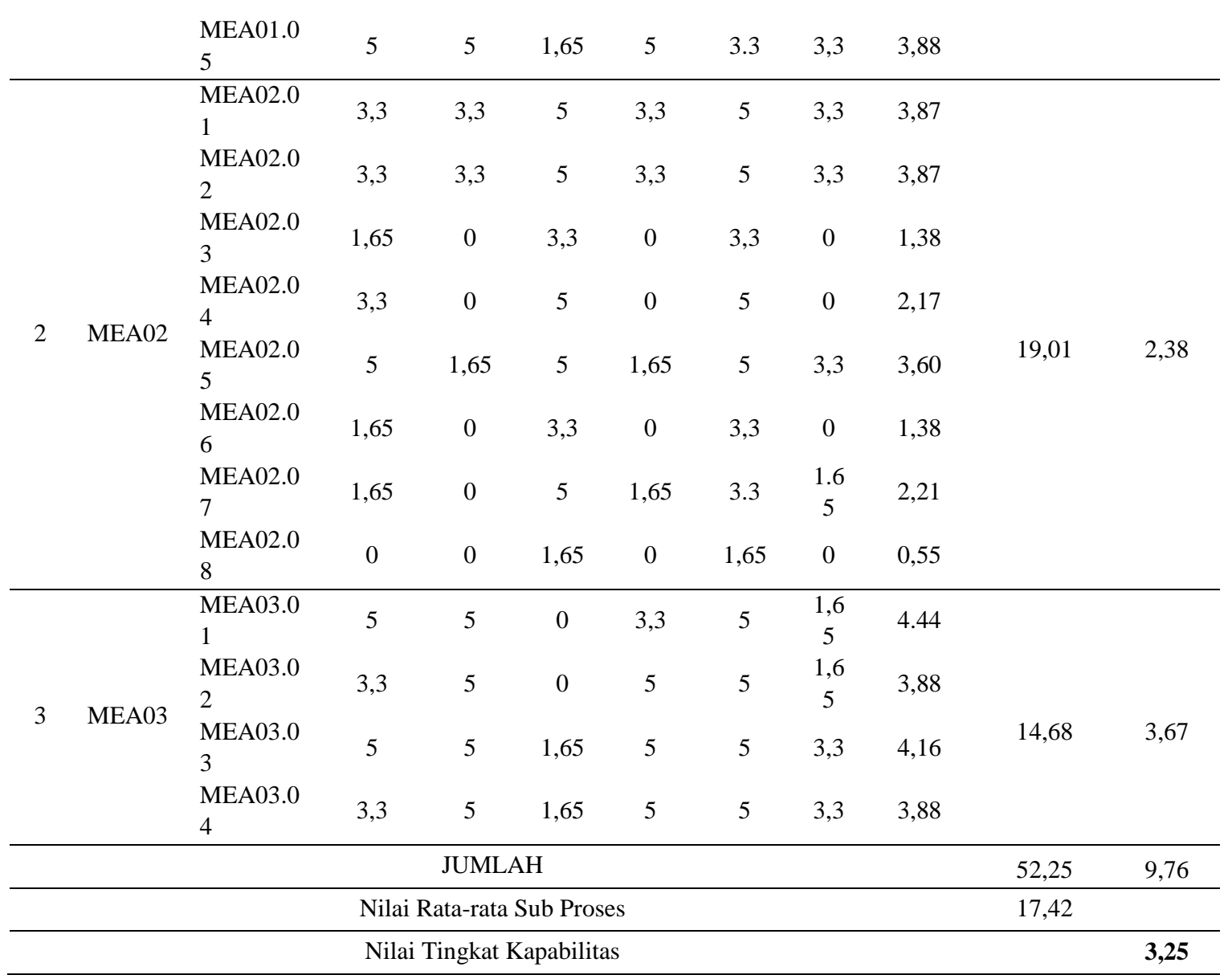

Dari hasil di atas, diketahui belum ada yang mencapai tingkat 5 atau tingkat capability Optimisting Process. Berdasarkan acuan dari pengeloan Barang Milik Negara Kemenku Permenku No. 171/PMK 05/2007, belum tercapainya tingkat kapabilitas $100 \%$, karena belum sesuai dengan tujuan penyelenggaraan SIMAK BMN yaitu untuk menghasilkan informasi yang diperlukan sebagai alat pertanggung jawaban atas pelaksanaan APBN serta pengelolaan/pengendalian Barang Milik Negara yang dikuasai oleh suatu unit akutansi barang.

Dari hasil kuesioner dan wawancara dengan pengawak SIMAK BMN ditemukan beberapa kendala intenal. Hal ini sesuai dengan hasil tingkat kapabilitas SIMAK BMN pada MEA02 yang berada pada tingkat 3. Permasalahan yang menonjol adalah pada penata usahaan BMN di Satker TNI AL masih belum optimal sehingga belum mencerminkan cara penatausahaan yang tertib dan benar. Penatausahaan tersebut belum mencerminkan suatu rangkaian kegiatan yang meliputi pembukuan, inventarisasi dan pelaporan BMN yang sesuai dengan ketentuan yang berlaku. Penatausahaan BMN belum mewujudkan tertib administrasi yang mendukung tertib pengelolaan BMN. Penatausahan BMN diperlukan untuk mendapatkan data sebaran kumulatif dengan tujuan penyusunan neraca pemerintah. Penatausahaan diperlukan untuk mendapatkan data secar rinci yang akan digunakan untuk perencanaan, pemeliharaan sampai dengan untuk prosess penghapusan.Berdasarkan hasil penilaian masing-masing proses yang telah diperoleh tersebut, maka dilakukan konfirmasi serta penelaahan melalui wawancara dengan pejabat pengawak SIMAK BMN pada domain Monitor, Evaluate, and Access (MEA). Hasil 
konfrmasi dan penelaahan pada setiap domain MEA adalah seperti pada Tabel 4 di bawah ini.

Tabel 3. Hasil Konfirmasi dan Penalaahan Penilaian Tingkat Kapabilitas SIMAK BMN

\begin{tabular}{|c|c|c|c|}
\hline $\mathrm{NO}$ & Standar & Kondisi saat ini & G/NG \\
\hline \multicolumn{4}{|c|}{ MEA01 } \\
\hline 1 & $\begin{array}{l}\text { Membangun dan memelihara dengan } \\
\text { pendekatan monitoring yang terintegrasi } \\
\text { dengan sistem manajemen kinerja dan selalu } \\
\text { ada tindakan perbaikan. }\end{array}$ & $\begin{array}{l}\text { Pengawasan dan monitoring terus dilakukan } \\
\text { untuk pengukuran dalam meningkatkan } \\
\text { kemampuan individu maupun organisasi }\end{array}$ & NG \\
\hline 2 & $\begin{array}{l}\text { Menganalisis dan melaporkan } \\
\text { kinerjanya }\end{array}$ & $\begin{array}{l}\text { Hasil kinerjanya selalu dilaporkan ke satuan } \\
\text { atas dan membuat pelaporan setiap semester }\end{array}$ & $\mathrm{G}$ \\
\hline 3 & $\begin{array}{l}\text { Mengumpulkan dan mengelola data tepat } \\
\text { waktu dan akurat. }\end{array}$ & $\begin{array}{l}\text { Pengelolaan data akan disajikan dalam bentuk } \\
\text { lapaoran intra maupun ektra berupa jurnal } \\
\text { aplikasi SIMAK BMN }\end{array}$ & G \\
\hline 4 & $\begin{array}{l}\text { Meninjau dan melaporkan kinerja SIMAK } \\
\text { BMN untuk mengatur target kinerja yang } \\
\text { telah ditetapkan }\end{array}$ & $\begin{array}{l}\text { Hasil kinerja SIMAK BMN sebagai tolak ukur } \\
\text { kinerja satker }\end{array}$ & G \\
\hline 5 & $\begin{array}{l}\text { Organisasi menggunakan laporan kontrol } \\
\text { internal unutuk menilai perbaikan }\end{array}$ & $\begin{array}{l}\text { Untuk memulai kontrol internal, pengawak } \\
\text { SIMAK selalu berkoordinasi dengan operator } \\
\text { unit pengguna barang tingkat UO TNI AL }\end{array}$ & $\mathrm{G}$ \\
\hline 6 & $\begin{array}{l}\text { Oraganisasi telah meningkatkan kesadaran } \\
\text { akan pengawasan Internal control }\end{array}$ & $\begin{array}{l}\text { Dalam organisasi telah dilakukan audit pada } \\
\text { laporan keuangan, tetapi TI sendiri tidak } \\
\text { dilakukan secara komprehensip terkendali pada } \\
\text { penguasaan TI SIMAK BMN }\end{array}$ & NG \\
\hline 7 & $\begin{array}{l}\text { Memantau internal dalam penyelenggaran } \\
\text { SIMAK BMN }\end{array}$ & $\begin{array}{l}\text { Penyelenggaraan Internal pada SIMAK BMN } \\
\text { akan selalu dipantau oleh pejabat terkait }\end{array}$ & G \\
\hline 8 & $\begin{array}{l}\text { Metodologi dan peralatan yang digunakan } \\
\text { untuk mengawasi internal kontrol mulai } \\
\text { digunakan tetapi bukan berdasarkan rencana }\end{array}$ & $\begin{array}{l}\text { Belum ada peralatan khusus yang dapat } \\
\text { mengawasi proses operasional TI SIMAK } \\
\text { BMN }\end{array}$ & NG \\
\hline \multicolumn{4}{|c|}{ MEA02 } \\
\hline 1 & $\begin{array}{l}\text { Organisasi menggunakan laporan kontrol } \\
\text { internal unutuk menilai perbaikan }\end{array}$ & $\begin{array}{l}\text { Untuk memulai internal kontrol pengawak } \\
\text { simak selalu berkoordinasi dengan operator } \\
\text { unit pengguna barang tingkat UO TNI AL }\end{array}$ & G \\
\hline 2 & $\begin{array}{l}\text { Oraganisasi telah meningkatkan kesadaran } \\
\text { akan pengawasan Internal }\end{array}$ & $\begin{array}{l}\text { Dalam organisasi telah dilakukan audit pada } \\
\text { laporan keuangan, tetapi TI sendiri tidak } \\
\text { dilakukan secara komperhensip terkendali pada } \\
\text { penguasaan TI SIMAK BMN }\end{array}$ & NG \\
\hline 3 & $\begin{array}{l}\text { Memantau kontrol internal dalam } \\
\text { penyelenggaran SIMAK BMN }\end{array}$ & $\begin{array}{l}\text { Penyelenggaraan Internal } \\
\text { penyelenggaraan SIMAK BMN akan } \\
\text { dipantau oleh pejabat terkait }\end{array}$ & G \\
\hline 4 & $\begin{array}{l}\text { Metodologi dan peralatan yang digunakan } \\
\text { untuk mengawasi kontrol internal mulai } \\
\text { digunakan tetapi bukan berdasarkan rencana }\end{array}$ & $\begin{array}{l}\text { Belum ada perlatan khusus yang dapat } \\
\text { mengawasi proses operasional TI SIMAK } \\
\text { BMN }\end{array}$ & NG \\
\hline \multicolumn{4}{|c|}{ MEA03 } \\
\hline 1 & $\begin{array}{l}\text { Secara terus menerus, mengidentifikasi dan } \\
\text { memonitor perubahan dalam undang-undang, } \\
\text { peraturan }\end{array}$ & $\begin{array}{l}\text { Pimpinan telah mendorong seluruh pengawak } \\
\text { SIMAK BMN untuk mematuhi aturan hukum } \\
\text { yang dikeluarkan oleh Kemenku, Kemhan, } \\
\text { TNI/TNI AL seperti pemberlakuan PMK, } \\
\text { Permen, PP, Perkasal dan Telegram }\end{array}$ & G \\
\hline 2 & $\begin{array}{l}\text { Mereview dan menyesuaikan kebijakan, } \\
\text { prinsip, standar, prosedur dan metodologi } \\
\text { untuk memastikan bahwa persyaratan hukum, } \\
\text { peraturan }\end{array}$ & $\begin{array}{l}\text { Peraturan yang telah dilaksanakan biasanya } \\
\text { dijadikan SOP (Standar Operasi Prosedur) } \\
\text { sebagai acuan oleh Pengawak SIMAK BMN. }\end{array}$ & G \\
\hline & Memastikan dipatuhinya kebijakan, prinsip, & Peraturan ekternal selain dikonfirmasikan & $\mathrm{G}$ \\
\hline
\end{tabular}




\section{Rekomendasi Pada Domain MEA}

Berdasarkan konfirmasi dan penelaahan pada Tabel 4., maka dilakukan rekomendasi perbaikan. Tahapan pertama rekomendasi adalah dengan memberikan rekomendasi pada proses yang masih berada pada tingkat 3 (Established Proces) agar meningkat pada tingkat 4 (Predictable Process). Tahap ke kedua memberikan rekomendasi agar proses yang masih berada pada tingkat 4 (Predictable Process) meningkat ke tingkat 5 (Optimisting Process). Rekomendasi agar tingkat kematangan TI SIMAK BMN meningkat pada masing-masing domain MEA adalah sebagai berikut:

\section{a. Tahap Pertama}

Berdasarkan pengukuran capability untuk proses MEA02 adalah pada tingkat 3 (Established Proces) target yang ingin dicapai adalah tingkat 4 (Predictable Proces). Pada Domian MEA02 ini menunjukkan pengaruh internal cukup besar sehingga gap cukup besar. Dengan kata lain sistem pengaksesan pada Sistem SIMAK BMN terjadi kekurang koordinasikan antar pihak pengelola pengguna Anggaran dengan pengelola Barang Milik Negara di Satker TNI AL. Untuk itu perlu adanya peningkatan terhadap kepatuhan didalam menginput data dan diperlukan evaluasi dan pengawasan secara melakat terhadap aplikasi SIMAK BMN.

b. Tahap Kedua

Berdasarkan pengukuran capability untuk proses MEA01 dan MEA03 adalah pada tingkat 4 (Predictable Proces) target yang ingin dicapai adalah tingkat 5 (Optimising Process). Pada Domian MEA01 didapat nilai rata-rata 3,7 hal ini menunjukkan pengases telah berjalan dengan baik dikarenakan tingkat kesenjangan bernilai positip. Dengan kata lain sistem pengaksesan pada Sistem SIMAK BMN sudah cukup baik untuk tetap dipertahankan dan terapkan. Faktor kemudahan dalam ases data SIMAK BMN adalah pengawak SIMAK BMN tidak perlu penghunbungi ke Paban SIMAK BMN karena data aplikasi sudah tersimpan pada sistem SIMAK BMN Satker TNI AL. Pada Domian MEA03 didapat nilai rata-rata 3,67 hal ini menunjukkan kepatuhan secara hukun telah berjalan dengan baik dikarenakan tingkat kesenjangan bernilai positip. Dengan kata lain sistem pengaksesan pada Sistem SIMAK BMN sudah cukup baik hal ini terus dipertahankan dan ditingkatkan sehingga dapat mencapai ke tingkat 5.

Hasil seluruh pengkuran atau tingkat kapabilitas tata kelola sistem SIMAK BMN di Satker TNI AL adalah berda pada tingkat 3 (Established Proces) artinya Satker TNI AL selaku satker pelapor UAKPB sudah mengimplementasikan tata kelola SIMAK BMN dengan cukup baik. Perbaikan secara terus menerus diperlukan melalui pengawasan dan penilaian. Selain itu, sosisialisasi setiap ada perubahan sistem versi terbaru diperlukan. Kebijaksanan pimpinan berupa telegram mupun regulasi yang dikeluarkan oleh Kementerian Pertahanan dan Kementerian Keuangan, rekomendasi tim pemeriksa Itjen maupun rekomendasi BPK perlu diikuti. Peningkatan terutama diperlukan melalui peningkatan kemampuan sumber daya manusia yang sering mendapatkan sorotan dari setiap pemeriksaan tim wasrik. 


\section{Simpulan}

Berdasarkan pengukuran yang telah dilakukan maka dapat disimpulkan bahwa, hasil dari rekapitulasi tingkat kapabilitas tata kelola Teknologi Informasi SIMAK BMN di Satker TNI AL adalah pada tingkat 3 (Established process). Hal ini menunjukkan bahwa Satker TNI AL selaku UAKPB sudah melaksanakan tata kelola SIMAK BMN dengan cukup baik. Namun masih diperlukan peningkatan terutama dari kemampuan sumber daya manusia yang sering mendapatkan sorotan dari setiap pemeriksaan tim pengawas dan pemeriksa (wasrik).

Saran penelitian lebih lanjut adalah perlu ditambahkan kriteria penilaian tata kelola teknologi informasi. Kriteria tersebut diperoleh dari nilai-nilai yang dapat dikuru secara kuantitatif, misalnya selisih (gap) antara data dalam sistema dengan kondisi nyata, dll.

\section{Daftar Pustaka}

Campbell, P. (2005). A COBIT Primer. Sandia Report SAND20053255. Sandia national Laboratories. Sandia Corporation. California. USA.

Budiono. (2010) Audit Kinerja Sistem Informasi Manajemen Pemeliharaan Unit Pembangkit Listrik Berbasis COBIT Domain. Jurnal EECCES, IV (1) 45-49

ISACA. (2012). A Business Framework for the Governance and Management of Enterprise IT. USA. ISACA.

Jamroni. (2006). Analisis Tingkat Kematangan Sistem Informasi Perpustakaan Surya Global Di STIKes Yogyakarta. Tesis STIMIK AMIKOM Yogyakarta.

Khanyile \& Abdullah. (2013). COBIT 5: an evolutionary framework and only framework to address the governance and management of enterprise IT. University of Africa (UNISA). Journal of IT, 5(3) 162-181.

Laksito. (2012). Analisis Model kematangan Tata Kelola Teknologi Informasi di STMIK AMIKO Menggunakan Framework COBIT. Tesis STMIK AMIKO Yogyakarta.

Mataracioglu \& Ozkan. (2012). Governing Information Security In Conjunction With COBIT And ISO 27001.

Middle Eas Technical University, Angkara Turkey.

Nugraha. (2012). Pengukuran Tingkat Kematangan Teknologi Informasi dengan Menggunakan Kerangka Kerja Cobit 4 Studi Kasus Pada PT XYZ. Tesis Magister. Universitas Indonesia. Jakarta.

O’Brien, J. A. \& Marakas G. (2005). Management Information System. Nine edition. Boston: Mc Graw Hill, Inc.

Sheikhpour and Modiri. (2012). An Approach to Map COBIT Processes to ISO/IEC 27001 Information Security Management Controls. International Journal of Security and Applications, 6 (2), 60-76.

Suranto, B., Hanum, F. F. \& Haryono, K. (2014). Audit Sistem Informasi Rsud Sleman Untuk Monitoring Dan Evaluasi Kinerja Sistem. Prosiding Seminar Nasional Informatika Medis (SNIMed) V 2014, Magister Teknik Informatika, Fakultas Teknologi Industri, Universitas Islam Indonesia, 48-57.

Sari, S. Rizal, S \& Santi, R. (2014). Penerapan Framework COBIT5 Pada Audit Tata Kelola teknologi Informasi di Dinas Komunikasi dan Informasi Kabupaten Oku. Jurnal Teknik Informasi 5 (2) pp.120-139.

Svata, V. (2011) IS Audit Consideration in Respect of Curren Economic Environment. University Of Economics in Prgague. Journal of system Integration . 7(3) 120-130.

Undang-Undang Nomor 1 tahun 2004 tentang Perbendaharaan Negara.Jakarta, Kementerian Keuangan Reublik Indonesia.

Lampiran. Pertanyaan pada Domain MEA01, MEA02 dan MEa03

\begin{tabular}{ll}
\hline Domain & Uraian \\
\hline MEA01 - Monitor, Evaluate, & Mengumpulkan, memvalidasi dan mengevaluasi bisnis, IT dan tujuan proses dan metrik. \\
\hline
\end{tabular}




\begin{tabular}{|c|c|}
\hline $\begin{array}{l}\text { and Assess Performance and } \\
\text { Conformance. }\end{array}$ & $\begin{array}{l}\text { Memantau bahwa proses berkerja terhadap kinerja dan kesesuaian tujuan dan persetujuan dan } \\
\text { memberikan pelaporan yang sistematis dan tepat waktu. }\end{array}$ \\
\hline $\begin{array}{l}\text { MEA01.01 } \\
\text { Establish a monitoring } \\
\text { approach. }\end{array}$ & $\begin{array}{l}\text { Terlibat dengan para pemangku kepentingan untuk membangun dan memelihara pendekatan } \\
\text { monitoring untuk menentukan tujuan, ruang lingkup dan metode untuk mengeveluasi solusi } \\
\text { bisnis dan pelayanan dan kontribusi terhadap tujuan perusahaan. Mengintegrasikan } \\
\text { pendekatan ini dengan sistem manajemen kinerja perusahaan }\end{array}$ \\
\hline $\begin{array}{l}\text { MEA01.02 } \\
\text { Set performance and } \\
\text { coformance targets }\end{array}$ & $\begin{array}{l}\text { Bekerja dengan para pemangku kepentingan untuk menentukan, meninjau secara berkala, } \\
\text { update dan menyetujui kinerja dan kesesuaian target dalam sistem pengukuran kinerja. }\end{array}$ \\
\hline $\begin{array}{l}\text { MEA01.03 } \\
\text { Collect \& process performance } \\
\& \text { conformance data }\end{array}$ & $\begin{array}{l}\text { Mengumpulkan dan mengolah data tepat waktu dan akurat sesuai dengan pendekatan } \\
\text { perusahaan. }\end{array}$ \\
\hline $\begin{array}{l}\text { MEA01.04 } \\
\text { Analyse and report } \\
\text { performance }\end{array}$ & $\begin{array}{l}\text { Berkala meninjau dan melaporkan kinerja terhadap target, menggunakan metode yang } \\
\text { menyediakan ringkas all-around pandangan kinerja TI dan cocok dalam sistem pemantauan } \\
\text { perusahaan }\end{array}$ \\
\hline $\begin{array}{l}\text { MEA01.05 } \\
\text { Ensure the implementation of } \\
\text { corrective actions }\end{array}$ & $\begin{array}{l}\text { Membantu para pemangku kepentingan dalam mengidentifikasi, memulai dan pelacakan } \\
\text { tindakan korektif untuk mengatasi anomali }\end{array}$ \\
\hline $\begin{array}{l}\text { MEA02 - Monitor, Evaluate, } \\
\text { and Assess the System of the } \\
\text { Internal Control }\end{array}$ & $\begin{array}{l}\text { Terus memantau dan mengevaluasi lingkungan pengendalian, termasuk penilaian diri dan } \\
\text { ulasan jaminan independen.Memungkinkan manajemen untuk mengidentifikasi kekurangan } \\
\text { kontrol dan infisiensi dan untuk memulai tindakan perbaikan. Merencanakan, mengatur dan } \\
\text { menjaga standar untuk kegiatan penilaian pengendalian internal dan jaminan. }\end{array}$ \\
\hline $\begin{array}{l}\text { MEA02.01 } \\
\text { Monitor internal controls }\end{array}$ & $\begin{array}{l}\text { Terus memantau, patokan dan memperbaiki lingkungan pengendalian TI dan kerangka kontrol } \\
\text { untuk memenuhi tujuan organisasi }\end{array}$ \\
\hline $\begin{array}{l}\text { MEA02.02 } \\
\text { Review business process } \\
\text { controls effectiveness }\end{array}$ & $\begin{array}{l}\text { Tinjau pengoperasian kontrol, termasuk peninjauan monitoring dan bukti uji, untuk } \\
\text { memastikan bahwa kontrol dalam proses bisnis beroperasi secara efektif. Meliputi kegiatan } \\
\text { untuk menjaga bukti operasi yang efektif kontrol melalui mekanisme seperti pengujian secara } \\
\text { berkala kontrol, kontrol terus menerus pemantauan, penilaian independen, pusat komando dan } \\
\text { pengendalian, dan pusat operasi jaringan. Ini menyediakan bisnis dengan jaminan efektivitas } \\
\text { kontrol untuk memenuhi persyaratan yang berkaitan dengan bisnis, peraturan dan tanggung } \\
\text { jawab sosial. }\end{array}$ \\
\hline $\begin{array}{l}\text { MEA02.03 } \\
\text { Perform control self- } \\
\text { assessments }\end{array}$ & $\begin{array}{l}\text { Mendorong manajemen dan pemilik proses untuk mengambil kepemilikan positif dari } \\
\text { peningkatan kontrol melalui program berkelanjutan dari self-assessment untuk mengevaluasi } \\
\text { kelengkapan dan efektivitas pengendalian manajemen atas proses, kebijakan dan kontrak. }\end{array}$ \\
\hline $\begin{array}{l}\text { MEA02.04 Identify and report } \\
\text { control deficiencies }\end{array}$ & $\begin{array}{l}\text { Mengidentifikasi kekurangan kontrol dan menganalisis dan mengidentifikasi akar penyebab } \\
\text { yang mendasarinya. Tingkatkan kekurangan kontrol dan melaporkan kepada stakeholder }\end{array}$ \\
\hline $\begin{array}{l}\text { MEA03 - Monitor, Evaluate, } \\
\text { and Assess Compliance with } \\
\text { External Requirements }\end{array}$ & $\begin{array}{l}\text { Menilai bahwa proses TI dan proses bisnis IT yang didukung telah sesuai dengan undang- } \\
\text { undang, peraturan dan persyaratan kontrak. Memperoleh keyakinan bahwa persyaratan telah } \\
\text { diidentifikasi dan dipenuhi, dan mengintegrasikan IT compliance dengan kepatuhan } \\
\text { perusahaan secara keseluruhan }\end{array}$ \\
\hline $\begin{array}{l}\text { MEA03.01 Identify external } \\
\text { compliance requirements }\end{array}$ & $\begin{array}{l}\text { Secara terus menerus, mengidentifikasi dan memonitor perubahan dalam undang-undang lokal } \\
\text { dan internasional, peraturan dan persyaratan eksternal lainnya yang harus dipenuhi dari } \\
\text { perspektif TI. }\end{array}$ \\
\hline $\begin{array}{l}\text { MEA03.02 Optimise response } \\
\text { to external requirements }\end{array}$ & $\begin{array}{l}\text { Review dan menyesuaikan kebijakan, prinsip, standar, prosedur dan metodologi untuk } \\
\text { memastikan bahwa persyaratan hukum, peraturan dan kontrak yang ditangani dan } \\
\text { dikomunikasikan. Pertimbangkan standar industri, kode praktek yang baik, dan bimbingan } \\
\text { praktek yang baik untuk adopsi dan adaptasi }\end{array}$ \\
\hline $\begin{array}{l}\text { MEA03.03 Confirm external } \\
\text { compliance }\end{array}$ & $\begin{array}{l}\text { Memastikan dipatuhinya kebijakan, prinsip, standar, prosedur dan metodologi dengan } \\
\text { persyaratan hukum, peraturan dan kontrak. }\end{array}$ \\
\hline $\begin{array}{l}\text { MEA03.04 Obtained assurance } \\
\text { of external compliance }\end{array}$ & $\begin{array}{l}\text { Mendapatkan dan melaporkan jaminan kepatuhan dan kepatuhan terhadap kebijakan, prinsip, } \\
\text { standar, prosedur dan metodologi. Konfirmasikan bahwa tindakan korektif untuk mengatasi } \\
\text { kesenjangan kepatuhan ditutup pada waktu yang tepat. }\end{array}$ \\
\hline
\end{tabular}

Sumber: ISACA, 2012 